\title{
Associations Between Night Sweats and Other Sleep Disturbances: An OKPRN Study
}

\author{
James W. Mold, MD, MPH \\ Joseph H. Woolley, BS \\ Zsolt Nagykaldi, $P b D^{1}$ \\ 'Department of Family and Preventive \\ Medicine, University of Oklahoma Health \\ Sciences Center, Oklahoma City, Okla \\ ${ }^{2}$ Creighton University Medical Center, \\ Omaha, Neb
}

\begin{abstract}
PURPOSE Surprisingly little is known about the causes and implications of night sweats. This study was designed to clarify further the associations between night sweats and sleep-related symptoms.

METHODS We undertook a cross-sectional study of consecutive adult patients seen in 10 primary care physicians' offices. Data were collected and transmitted by a personal digital assistant. Information included demographic variables; height, weight, and blood pressure; occurrence of a variety of sleep-related symptoms; and occurrence and severity of night sweats, day sweats, and hot flashes in the past month. For women, information about menstrual status was also obtained.
\end{abstract}

RESULTS Thirty-four percent of the 363 patients interviewed reported night sweats, one half of whom reported saturating their bedclothes. In the multivariate model, night sweats were associated with daytime tiredness (OR $=1.99$; $95 \% \mathrm{Cl}, 1.12-3.53)$, waking up with a bitter taste in the mouth $(\mathrm{OR}=1.94$; $95 \% \mathrm{Cl}, 1.19-3.18)$, legs jerking during sleep (OR $=1.78 ; 95 \% \mathrm{Cl}, 1.05-3.00)$, and awakening with pain in the night $(\mathrm{OR}=1.87 ; 95 \% \mathrm{Cl}, 1.16-2.99)$.

CONCLUSIONS Night sweats are associated with several sleep symptoms. Both night sweats and sleep disturbances are commonly experienced by adult primary care patients. When their patients report night sweats, clinicians should consider asking about sleep quality and sleep-related symptoms.

Ann Fam Med 2006:4:423-426. DOI: 10.1370/afm.554

\section{INTRODUCTION}

lthough night sweats (a symptom of serious systemic diseases,
such as tuberculosis, lymphoma, and autoimmune diseases) have
generally been believed to be relatively uncommon, we and others have documented that their prevalence is much higher than previously thought..$^{1-3}$ Among patients queried in the offices of primary care physicians, as many as $41 \%$ reported having experienced night sweats in the prior month, and one half of them experienced excessive sweating only at night. In male participants, after controlling for other variables, night sweats were found to be associated with sleep problems.

It makes sense that certain sleep disorders, such as sleep apnea, periodic leg movements during sleep, painful arousals, and frightening dreams might cause night sweats; in fact, though little evidence exists, these disorders have been included on some lists of possible causes. ${ }^{4,5}$ It is also possible that nocturnal sweating might disrupt sleep, or that individuals with poorer sleep quality might be more likely to awaken to notice that they are sweating and thus be more likely to report it.

A preliminary study to more definitive studies on the nature of any such relationships, this study was undertaken to gather additional information on potential associations between night sweats and symptoms of specific sleep disorders. 


\section{METHODS}

We invited physician members of the Oklahoma Physicians Resource/Research Network (OKPRN) to participate in this study. On 3 consecutive days in 2001, participating physicians or their nurses requested informed consent and enrolled as many consecutive adult patients as possible until they began to fall behind on their office schedules. Using a personal digital assistant (PDA), they asked patients a series of questions and entered their answers directly into the PDA. The PDA questionnaire, which was programmed in PenDragon Internet Forms (PenDragon ${ }^{\circledR}$ Software Corp, Libertyville, Ill), incorporated branching logic (eg, only women with night sweats answered questions about menstrual periods), field limits (answers outside reasonable ranges were not accepted), and forced answers (each question had to be answered before the program would move to the next question). When the PDAs were synchronized each night, the data were transferred to a database on a central file server.

Data for the following variables were collected: agegroup (18-40, 41-55, 56-69, and $\geq 70$ years), sex, race (white, nonwhite), ethnicity (Hispanic, non-Hispanic), sleep latency ( $\leq 5$ or $\geq 15$ minutes), sleep duration $(\leq 6$ hours or $>6$ hours), restless or fidgety legs (yes or no), nocturnal awakenings ( $<2$ or $\geq 2$ times per night), pain causing sleep disruption (yes or no), snoring (yes or no), snore frequency $(<1$ time a week or $>1$ time a week), snore severity (less than, as loud as, or louder than talking), awakening with a choking sensation or sour/bitter taste in mouth (yes or no), legs jerk during sleep (yes or no), daytime tiredness (categorical and dichotomized as $<1$ time a week or $>1$ time a week), having fallen asleep while driving in the past year (yes or no), night sweats in past month (yes or no), day and nighttime sweating in past month (yes or no), and saturation of bed linens with sweat (yes or no). Patients were asked, "During the past month, have you noticed that you sweat excessively at night even when it isn't too hot in your bedroom?" This question is essentially the same as that used in our previous studies. Women were asked about hot flashes (yes or no), use of female hormones (yes or no), currently having menstrual periods (yes or no), and number of years since last period. Weight, height, and blood pressure were recorded for the first 281 patients only, so these variables were not included in regression models. We also did not include any of the female-specific questions in the models. In both the bivariate and multivariate analyses, we combined patients with night sweats only and those with both day and night time sweating into a single group (night sweats).

The data were analyzed in Statistix 8.0 (Analytical Software, Tallahassee, Fla). We used $\chi^{2}$ (for categorical variables) and independent Student $t$ tests (for continu- ous variables) for the bivariate analyses. Associations with $P$ values <.05 were considered to be statistically significant. Variables with bivariate $P$ values $<.10$ were entered into a multivariate logistic model with night sweats as the dependent variable. Variables were then removed one at a time based upon highest $P$ value until the most parsimonious model was determined.

The study was approved by the Institutional Review Board of the University of Oklahoma Health Sciences Center. Data was collected between July and December.

\section{RESULTS}

Ten physicians agreed to participate. Of the 375 patients approached, 364 agreed to be enrolled (97\%). The median number of patients enrolled per physician was 23 (range: 2-75). One patient had a missing value for the dependent variable, night sweats, leaving 363 patient data sets for evaluation. The data were remarkably complete otherwise, with only 31 of a possible 8,966 data points $(0.3 \%)$ missing. The characteristics of the sample are shown in Table 1 . The mean body mass index (BMI) of the first 281 patients was $31.2(\mathrm{SD}=7.7)$.

One hundred twenty-three patients (33.9\%) reported that they had experienced night sweats in the past month, with approximately one half reporting night sweats only, and the rest reporting both night and day sweats. Fifty percent of patients who reported night sweats of either type said that they sweated enough to soak through their bedclothes.

All but 3 patients (99\%) reported at least 1 of the sleep-related symptoms included in this study (median, 5 symptoms per patient). The total number of sleeprelated symptoms was strongly associated with night sweats $(P<.0001)$. Bivariate associations between specific sleep symptoms and night sweats are shown in Table 1. The occurrence of night sweats was unrelated to age, sex, or race. Among the 281 patients whose blood pressure was measured, systolic blood pressure was higher among those who reported night sweats (means, 133.4 vs $127.5 \mathrm{~mm} \mathrm{Hg}{ }_{i} P=.02$ ) and diastolic pressure tended to be a little higher as well (means, 80.9 vs $78.0 \mathrm{~mm} \mathrm{Hg}_{i} P=.09$ ).

There was no association between snoring (yes or no), snore frequency, or snore volume (loudness) and night sweats. In the initial 281 patients, increased BMI was associated with snoring $(P=.03)$ but not with the frequency or volume of snoring among those who snored. The association between BMI and night sweats nearly reached statistical significance $(P=.06)$. Eighteen percent of participants reported having fallen asleep while driving at least once during the past year. There was no association between night sweats and having fallen asleep while driving. 


\begin{tabular}{|c|c|c|c|}
\hline Variables & Number & $\begin{array}{c}\text { Night Sweats } \\
n(\%)\end{array}$ & $P$ Value \\
\hline Study sample & 363 & $123(34)$ & \\
\hline \multicolumn{4}{|l|}{ Age } \\
\hline $18-40 y$ & 105 & $32(30)$ & .19 \\
\hline $41-55$ y & 127 & $52(41)$ & \\
\hline $56-69 y$ & 102 & $30(29)$ & \\
\hline $70+y$ & 30 & $9(30)$ & \\
\hline \multicolumn{4}{|l|}{ Sex } \\
\hline Female & 215 & $75(35)$ & .66 \\
\hline Men & 147 & $48(33)$ & \\
\hline \multicolumn{4}{|l|}{ Race } \\
\hline White & 326 & $110(34)$ & .41 \\
\hline Black & 18 & $4(22)$ & \\
\hline Other & 16 & $7(44)$ & \\
\hline \multicolumn{4}{|l|}{ Ethnicity } \\
\hline Non-Hispanic & 357 & $120(34)$ & .08 \\
\hline Hispanic & 4 & $3(75)$ & \\
\hline \multicolumn{4}{|l|}{ Sleep latency } \\
\hline$\leq 15 \min$ & 188 & $52(28)$ & .01 \\
\hline$>15 \min$ & 174 & $70(40)$ & \\
\hline \multicolumn{4}{|l|}{ Sleep duration } \\
\hline$\leq 6 \mathrm{hr}$ & 173 & $54(31)$ & .29 \\
\hline$>6 \mathrm{hr}$ & 189 & $69(37)$ & \\
\hline \multicolumn{4}{|l|}{ Awakening } \\
\hline$\leq 2$ times per night & 49 & $8(16)$ & .005 \\
\hline$>2$ times per night & 313 & $115(37)$ & \\
\hline \multicolumn{4}{|l|}{ Pain } \\
\hline No & 186 & $45(24)$ & .0001 \\
\hline Yes & 177 & $78(44)$ & \\
\hline \multicolumn{4}{|l|}{ Snoring } \\
\hline No & 129 & $41(32)$ & .53 \\
\hline Yes & 234 & $82(37)$ & \\
\hline \multicolumn{4}{|l|}{ Snore frequency } \\
\hline Less than weekly & 225 & $72(32)$ & .33 \\
\hline Weekly or more & 138 & $51(37)$ & \\
\hline \multicolumn{4}{|l|}{ Snore volume } \\
\hline Talking or less & 236 & $73(31)$ & .11 \\
\hline Louder than talking & 127 & $50(39)$ & \\
\hline \multicolumn{4}{|l|}{ Daytime tiredness } \\
\hline$\leq 2$ times a week & 103 & $20(19)$ & .0002 \\
\hline$>2$ times a week & 260 & $103(40)$ & \\
\hline \multicolumn{4}{|l|}{ Fidgety legs } \\
\hline No & 230 & $63(27)$ & .0006 \\
\hline Yes & 133 & $60(45)$ & \\
\hline \multicolumn{4}{|l|}{ Legs jerk } \\
\hline No & 280 & $83(30)$ & .002 \\
\hline Yes & 83 & $40(48)$ & \\
\hline \multicolumn{4}{|l|}{ Sour/bitter taste } \\
\hline No & 257 & $71(28)$ & .0001 \\
\hline Yes & 106 & $52(49)$ & \\
\hline
\end{tabular}

Neither the frequency nor the severity of night sweats was associated with gender. Most (54\%) women with night sweats reported hot flashes as well. One third of the women who reported night sweats were still menstruating. Three quarters of the postmenopausal women with night sweats were taking exogenous hormones. Women were more likely than men to report increased sleep latency $(P=.003)$. They were less likely to report snoring $(P=.007)$ or having fallen asleep while driving $(P=.01)$.

The multivariate model is displayed in Table 2. After controlling for other variables, the sleep symptoms associated with night sweats included daytime tiredness $(P=.02)$, awaking with a bitter taste in the mouth $(P=.008)$, jerking of legs during sleep $(P=.03)$, and waking in the night with pain $(P=.01)$.

\section{DISCUSSION}

This study expands upon earlier findings regarding associations between subjective (reported) night sweats and other symptoms in primary care populations. It supports the conclusion that night sweats are commonly experienced or reported by adults who visit primary care physicians. Thirty-three percent of patients reported experiencing night sweats, with $16 \%$ reporting nighttime sweating severe enough to soak their bedclothes.

Night sweats appear to be associated with a variety of sleep symptoms, though the nature of the associations is unclear. It could be that night sweats are in some way caused by specific sleep syndromes, such as periodic leg movements in sleep or restless legs syndrome. Alternatively, patients who wake up in the night because of these sleep syndromes may simply be more likely to notice and report night sweats, or both the sleep symptoms and night sweats are associated with a third factor, such as anxiety or depression or medications. In any case, a history of night sweats should probably prompt the clinician to ask more questions about sleep.

Sleep symptoms are also common among primary care patients. Almost every patient (99\%) had at least 1 symptom, and the median number of symptoms per patient was 5 . The most common sleep symptoms reported were frequent awakenings and daytime drowsiness. Given the importance of sleep to health, this finding reinforces the need to ask patients about sleep problems. In fact, anecdotally, the clinicians and nurses involved in the study commented on how often they found the answers to the survey questions surprising and informative.

Limitations of the study include its cross-sectional design, the relatively small number of participants, and the subjectivity of the data. As pointed out above, 


\begin{tabular}{|c|c|c|c|c|}
\hline Variables & Coefficient & $\begin{array}{l}\text { Standard } \\
\text { Error }\end{array}$ & $\begin{array}{l}\text { Odds } \\
\text { Ratios }\end{array}$ & $\begin{array}{l}95 \% \text { Confidence } \\
\text { Intervals }\end{array}$ \\
\hline Constant tiredness & -1.87 & 0.28 & --- & \\
\hline Daytime tiredness & 0.69 & 0.29 & 1.99 & $1.12-3.53$ \\
\hline Acid reflux* & 0.66 & 0.25 & 1.94 & $1.19-3.18$ \\
\hline Legs jerk in sleep & 0.58 & 0.27 & 1.78 & $1.05-3.00$ \\
\hline Awaken with pain & 0.62 & 0.24 & 1.87 & $1.16-2.99$ \\
\hline
\end{tabular}

probably be queried about sleep quality and sleep-related symptoms.

To read or post commentaries in response to this article, see it online at http://www. annfammed.org/cgi/content/full/4/5/423.

Key words: Night sweats; sleep disorders; hot flashes; primary health care; practice-based research network

Submitted September 21, 2005; submitted, revised, January 9, 2006; accepted January 16, 2006. however, the cause is perhaps not so important in this

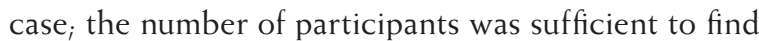
several interesting associations, and symptoms are by their very nature subjective. Because single questions were used to determine whether patients had particular types of sleep problems, it would be inappropriate to assume that the symptoms identified were synonymous with specific sleep disorders. So, for example, restless legs may or may not be the same as restless legs syndrome. Likewise, the lack of association between night sweats and snoring should not be taken as proof that night sweats are not a symptom of sleep apnea. Further studies should look at longitudinal data and at patients with more definitive evidence of sleep disorders. It might be informative to question bed partners as well to find out whether there is consistency of reporting.

Night sweats are associated with a variety of sleep symptoms. Both night sweats and sleep disturbances are commonly experienced by adult primary care patients. Patients complaining of night sweats should
Funding support: Funds for this project were provided by the Agency for Healthcare Research and Quality, grant \#R21 HS13557-01.

Acknowledgments: We would like to acknowledge and thank Drs. Mike Aaron, Dee Legako, Kevin O'Brien, Paul Preslar, Scott Stewart, Dan Woiwode, Mike Pontious, Terrill Hulson, Nathan Boren, and Peter Winn for their participation in this project.

\section{References}

1. Reynolds WA. Are night sweats a sign of esophageal reflux? J Clin Gastroenterol. 1989;11:590-591.

2. Mold JW, Mathew MK, Belgore S, DeHaven M. Prevalence of night sweats in primary care patients: an OKPRN and TAFP-Net collaborative study. J Fam Pract. 2002;51:452-456.

3. Mold JW, Roberts M, Aboshady HM. Prevalence and predictors of night sweats, day sweats, and hot flashes in older primary care patients: an OKPRN study. Ann Fam Med. 2004;2:391-397.

4. Viera AJ, Bond MM, Yates SW. Diagnosing night sweats. Am Fam Physician. 2003;67:1019-1024.

5. Kahn A, Groswasser J, Sottiaux M, et al. Clinical symptoms associated with brief obstructive sleep apnea in normal infants. Sleep. 1993;16:409-413. 